\title{
Redes neurais artificiais para a modelagem do volume de madeira e biomassa do cerradão com dados de satélite
}

\author{
Eder Pereira Miguel(1), Alba Valéria Rezende(1), Fabrício Assis Leal(1), Eraldo Aparecido Trondoli Matricardi(1), \\ Ailton Teixeira do Vale ${ }^{(1)}$ e Reginaldo Sérgio Pereira(1)
}

(1)Universidade de Brasília, Faculdade de Tecnologia, Departamento de Engenharia Florestal, Campus Darcy Ribeiro, CEP 70910-900 Brasília, DF, Brasil. E-mail: miguelederpereira@gmail.com, albavr@unb.br, fabricioassisleall@gmail.com, ematricardi@gmail.com, ailton.vale@gmail.com, reginaldosergiopereira@gmail.com

\begin{abstract}
Resumo - O objetivo deste trabalho foi avaliar a eficácia da aplicação de modelos de análise de regressão e redes neurais artificiais (RNAs) na predição do volume de madeira e da biomassa acima do solo, da vegetação arbórea em área de cerradão. Volume de madeira e biomassa foram estimados com equações alométricas desenvolvidas para a área de estudo. Os índices de vegetação, como variáveis preditoras, foram estimados a partir de imagens do sensor LISS-III, e a área basal foi determinada por medições na floresta. A precisão das equações foi verificada pela correlação entre os valores estimados e observados (r), erro-padrão da estimativa (Syx) e gráfico residual. As equações de regressão para o volume de madeira total e do fuste $(0,96$ e 0,97 para r, e 11,92 e $9,72 \%$ para Syx, respectivamente) e para a biomassa (0,91 e 0,92 para r, e 22,73 e 16,80\% para Syx, respectivamente) apresentaram bons ajustes. As redes neurais também apresentaram bom ajuste com o volume de madeira (0,99 e 0,99 para r, e 4,93 e 4,83\% para Syx) e a biomassa $(0,97$ e 0,98 r, e 8,92 e 7,96\% para Syx, respectivamente). A área basal e os índices de vegetação foram eficazes na estimativa do volume de madeira e biomassa para o cerradão. Os valores reais de volume de madeira e biomassa não diferiram estatisticamente dos valores estimados pelos modelos de regressão e redes neurais $\left(\chi^{2 \mathrm{~ns}}\right)$; contudo, as RNAs são mais acuradas.

Termos para indexação: índice de vegetação, inventário florestal, produção, regressão, sensoriamento remoto.

\section{Artificial neural networks for modeling wood volume and aboveground biomass of tall Cerrado using satellite data}

\begin{abstract}
The objective of this work was to evaluate the effectiveness of regression models and artificial neural networks (ANNs) in predicting wood volume and aboveground biomass of arboreal vegetation in area of tall Cerrado (a forest, savanna-like vegetation). Wood volume and biomass were estimated with allometric equations developed for the studied area. The vegetation indices, as predictor variables, were estimated from LISS-III sensor imagery, and the basal area was determined from field measurements. Equation precision was verified by the correlation between estimated and observed values (r), standard error of estimate (Syx), and by the residual plot. The regression equations for total wood volume and bole volume ( 0.96 and 0.97 for $\mathrm{r}$, and 11.92 and $9.72 \%$ for Syx, respectively), as well as for aboveground biomass ( 0.91 and 0.92 for $\mathrm{r}$, and 22.73 and $16.80 \%$ for Syx, respectively) showed good adjustments. The neural networks also showed good adjustments for both wood volume ( 0.99 and 0,99 for $\mathrm{r}$, and 4.93 and $4.83 \%$ for Syx) and biomass $(0.97$ and 0.98 for $\mathrm{r}$, and 8.92 and $7.96 \%$ for Syx, respectively). Basal area and vegetation indices were effective in estimating wood volume and biomass for the tall cerrado vegetation. Measured wood volume and aboveground biomass did not differ statistically from the predicted values by both the regression models and neural networks $\left(\chi^{2 \mathrm{~ns}}\right)$; however, the ANNs are more accurate.
\end{abstract}

Index terms: vegetation index, forest inventory, production, regression, remote sensing.

\section{Introdução}

A perda de cobertura vegetal, na maioria dos ecossistemas tropicais, tem sido uma das grandes preocupações mundiais nas últimas décadas, principalmente pelo importante papel que eles têm no ciclo global do carbono (Djomo et al., 2011), por armazená-lo na vegetação e no solo e liberar oxigênio para a atmosfera (Rasche et al., 2013). A degradação ou conversão destes ecossistemas para outros usos resulta, quase sempre, na fragmentação dos ambientes, e ocasiona elevadas perdas de biodiversidade.

No entanto, mesmo diante das transformações que vêm ocorrendo no bioma nas últimas décadas, o 
Cerrado ainda é considerado uma das savanas mais ricas em diversidade (Mendonça et al., 2008).

Entre as formações florestais do Cerrado, destaca-se o cerradão que está geralmente associado a áreas de interflúvio, terrenos bem drenados e solos profundos (Ribeiro \& Walter, 2008), da classe dos Latossolos, e que pode ocorrer também em Cambissolos distróficos (Solorzano et al., 2012). Atualmente, os cerradões são encontrados em pequenos fragmentos isolados ou em contato com outras fitofisionomias do Cerrado, como cerrado stricto sensu, mata de galeria e mata seca ou floresta estacional (Guilherme \& Nakajima, 2007).

Dos estudos já realizados em áreas de cerradão, a grande maioria trata apenas da caracterização de sua flora (composição, riqueza e diversidade) e da estrutura de sua vegetação. Raríssimos são os estudos relacionados à produção desta fitofisionomia, seja em termos de volume de madeira ou de estoques de biomassa e de carbono. Para Rezende et al. (2006), a escassez de informações sobre estas variáveis, nas diferentes fitofisionomias do Cerrado, está relacionada principalmente à grande diversidade de espécies e, também, à alta variabilidade de forma do fuste e copa das árvores, mesmo de árvores de uma mesma espécie.

A quantificação da biomassa acima do solo em formações tropicais é de fundamental importância para a compreensão da dinâmica dos fluxos de carbono entre os ecossistemas terrestres e a atmosfera (Cutler et al., 2012). Em geral, sua predição é feita a partir do uso de ferramentas matemáticas, como equações alométricas e fatores de expansão ou redução. Mais recentemente, novas técnicas de predição com redes neurais artificiais (RNAs) e imagens de satélite (Almeida et al., 2014) têm sido também utilizadas. Porém, Watzlawick et al. (2009) afirmam que a utilização de imagens de satélite na quantificação da produção florestal ainda é pouco usada, sobretudo em florestas heterogêneas, em razão da alta diversidade florística e fisionômica. Contudo, o uso de imagens de satélite, para estimar e prognosticar a produção florestal quanto ao volume de madeira e biomassa, pode ser considerada uma técnica mais fácil e menos onerosa para obtenção de dados. Além disso, esta técnica permite a obtenção de informações sobre áreas remotas e inacessíveis.

Todavia, quanto ao processo de predição, há erros que, na maioria das vezes, estão associados apenas à qualidade das informações e resoluções dos sensores. Portanto, melhores algoritmos de processamento e técnicas de análise de dados podem aumentar a precisão das estimativas (Baccini et al., 2007).

Em particular, quanto ao bioma Cerrado, em que a produção lenhosa (biomassa e volume) de suas fisionomias ainda é pouco conhecida. Portanto, é importante avaliar a aplicabilidade de diferentes técnicas que permitam estimar com precisão estas variáveis.

O objetivo deste trabalho foi avaliar a eficácia da aplicação de modelos de análise de regressão e redes neurais artificiais (RNAs) na predição do volume de madeira e da biomassa acima do solo, da vegetação arbórea em área de cerradão.

\section{Material e Métodos}

O estudo foi realizado em um fragmento de cerradão de 12,2 hectares, situado entre os paralelos $10^{\circ} 10^{\prime} 55^{\prime \prime}$ e $10^{\circ} 11^{\prime} 20^{\prime \prime} \mathrm{S}$ e entre os meridianos $48^{\circ} 10^{\prime} 50^{\prime \prime}$ e $48^{\circ} 10^{\prime} 30^{\prime \prime} \mathrm{W}$, no Município de Palmas, TO. O solo predominante na área é o Latossolo Vermelho-Escuro distrófico álico (Santos et al., 2013). O relevo é plano-ondulado, e o clima é do tipo C2wA'a', conforme a classificação de Köppen, com valores pluviométricos que chegam a $1.700 \mathrm{~mm}$ por ano.

O cerradão é caracterizado como distrófico (Solorzano et al., 2012), com sub-bosque ralo e aberto. A comunidade apresenta cerca de 1.228 árvores ha ${ }^{-1}$, inclusive árvores vivas e mortas em pé, com diâmetro à altura do peito (DAP) acima de ou igual a $5 \mathrm{~cm}$, que correspondem à área basal total de $17,34 \mathrm{~m}^{2} \mathrm{ha}^{-1}$. As árvores vivas estão distribuídas em 82 espécies, 60 gêneros e 34 famílias. Predominam na área: as famílias Fabaceae, Chrysobalanaceae e Vochysiaceae; os gêneros Licania, Byrsonima e Qualea e as espécies Myrcia splendens, Emmotum nitens e Qualea parviflora (Miguel, 2014). O inventário florestal do fragmento de cerradão foi feito de março a junho de 2012, tendo-se utilizado o processo de amostragem sistemático com parcelas de área fixa (Péllico Netto \& Brena, 1997).

Para efeito de inventário, implantaram-se no fragmento oito transectos com $20 \mathrm{~m}$ de largura e comprimento variável, equidistantes em $60 \mathrm{~m} \mathrm{e}$ perpendiculares à declividade maior do fragmento. Cada transecto foi subdividido em parcelas de $400 \mathrm{~m}^{2}$ (20x20m), que foram alocadas e georreferenciadas com o uso de um receptor de sistema de posicionamento global GPSMAP 62S (Garmin International Inc., Olathe, KS, EUA). 
No total, alocaram-se 54 parcelas de $400 \mathrm{~m}^{2}$, o que corresponde a 2,16 ha amostrados. Em cada parcela, amostraram-se e identificaram-se todas as árvores vivas e mortas em pé, com DAP tomado à $1,30 \mathrm{~m}$ do solo igual ou superior a $5 \mathrm{~cm}$. Os diâmetros foram medidos por meio de suta, e as alturas, total (Ht) e do fuste (Hf), com régua telescópica. Para árvores com altura superior a $15 \mathrm{~m}$, suas alturas foram estimadas, com o hipsômetro Vertex IV (Haglöf, Estocolmo, Suécia).

As variáveis densidade, área basal, volume de madeira e biomassa seca foram registradas em cada parcela. $\mathrm{O}$ volume de madeira e a biomassa de cada árvore foram estimados por meio de equações alométricas, desenvolvidas e validadas para o cerradão estudado. Tais equações foram ajustadas tanto para o fuste quanto para o total (fuste + copa) e são dadas por, Vtotal $=0,000085 \times \mathrm{DAP}^{2,12227} \times \mathrm{Ht}^{0,66621}\left(\mathrm{R}^{2}=0,99\right)$, Vfuste $=0,0001063 \times \mathrm{DAP}^{1,79116} \times \mathrm{Ht}^{0,792509}\left(\mathrm{R}^{2}=0,96\right)$, Btotal $=0,0123307 \times \mathrm{DAP}^{1,79593} \times \mathrm{Ht}^{1,54701}\left(\mathrm{R}^{2}=0,97\right) \mathrm{e}$ Bfuste $=0,0208857 \times \mathrm{DAP}^{1,47985} \mathrm{x} \mathrm{Ht}^{1,39106}\left(\mathrm{R}^{2}=0,96\right)$, em que: Vtotal é o volume total da árvore, em $\mathrm{m}^{3}$; Vfuste é o volume do fuste, $\mathrm{em}^{3}$; Btotal é a biomassa da árvore seca total, em kg; e Bfuste é a biomassa do fuste seco, em $\mathrm{kg}$ (Miguel, 2014). As estimativas de volume de madeira e biomassa, por parcela, foram obtidas pelo somatório dos valores individuais destas variáveis registrados em cada parcela.

A partir dos valores de volume de madeira e biomassa seca, estimados para cada uma das 54 parcelas amostradas, foram aleatoriamente selecionadas 40 parcelas para o ajuste de modelos de regressão e RNAs, para a predição do volume de madeira e biomassa seca da vegetação arbórea do cerradão por unidade de área, em função da variável área basal $(\mathrm{G})$ da parcela (variável dendrométrica) e de variáveis geradas por sensoriamento remoto. As 14 parcelas restantes foram utilizadas na validação dos modelos selecionados.

A área basal $(\mathrm{G})$ é obtida a partir de dados de campo e é dada por: $\mathrm{G}$ por parcela $=\sum\left(\pi \times \mathrm{DAP}^{2} / 40.000\right)$. A utilização da área basal como variável preditora se justifica pela facilidade de sua obtenção, pela alta correlação com as variáveis volume de madeira e biomassa, e pela associação intrínseca com o grau de aproveitamento dos fatores de crescimento e produção local (Husch et al., 1982).

As variáveis geradas a partir de dados de sensoriamento remoto foram: SR, índice de vegetação de razão simples (Jordan, 1969); NDVI, índice de vegetação de diferença normalizada (Rouse et al., 1973); $\mathrm{EVI}_{2}$, índice de vegetação modificado (Jiang et al., 2008); e Savi, índice de vegetação ajustado ao solo (Huete, 1988). Estes índices foram obtidos a partir de dados do sensor LISS-III ("linear imaging self-scanner"), a bordo do satélite ResourceSat1 (IRS-P6). O IRS-P6 tem resolução espacial de 23,5 m para todos os canais espectrais (B2 com $0,52-0,59 \mu \mathrm{m}$, B3 com 0,62-0,68m, B4 com 0,77-0,86 $\mu \mathrm{m}$, e B5 com 1,55-1,70 $\mu \mathrm{m})$. A escolha do sensor LISS-III se deu pelo fato de sua resolução espacial ser próxima ao tamanho da unidade amostral adotada nesse trabalho. A cena do satélite IRS-P6 utilizada neste estudo foi a 327/84, registrada em 30 de junho de 2012. A data da imagem coincidiu com o término dos trabalhos de campo.

Para o georreferenciamento da imagem, utilizaramse dez pontos de controle obtidos em campo, com o uso do GPSMAP 62S, e o modelo polinomial de primeira ordem com reamostragem por vizinho mais próximo. Os sistemas de projeção cartográfica e de referência utilizados foram, respectivamente, o UTM ("universal transversa de Mercator") e o Datum WGS 84 (World Geodetic System). O erro médio quadrático foi utilizado como parâmetro para avaliar a precisão do georreferenciamento. Os efeitos da atmosfera sobre os números digitais da imagem foram corrigidos com o uso do algoritmo Flaash ("fast line-of-sight atmospheric analysis of spectral hypercubes") (Vivaldi et al., 2013). Os principais parâmetros utilizados foram: tipo do sensor, LISS-III; altitude do sensor, $817 \mathrm{~km}$; tamanho de pixel, 23,5 m; modelo atmosférico, tropical; espessura da coluna de água, 2; modelo de aerosol, rural; e visibilidade inicial, $40 \mathrm{~km}$.

Após a correção atmosférica, estimaram-se os quatro índices de vegetação, SR, NDVI, $E I_{2}$ e Savi, obtidos pelas seguintes equações matemáticas: $\mathrm{SR}=\mathrm{NIR} / \mathrm{RED}$; NDVI = (NIR - RED $) /(\mathrm{NIR}+\mathrm{RED})$; $\mathrm{EVI}_{2}=2,5[(\mathrm{NIR}-\mathrm{RED}) /(\mathrm{NIR}+2,4 \mathrm{RED}+1)] ; \mathrm{e}$ Savi $=[(1+\mathrm{L})(\mathrm{NIR}-\mathrm{RED})] / \mathrm{NIR}+\mathrm{RED}+\mathrm{L}$; em que: NIR é a reflectância na banda do infravermelho próximo; RED é a reflectância na banda do vermelho; L é a constante de ajuste do solo $(0,5) ; 2,5$ é o fator de ganho; 2,4 e 1 são as constantes.

Para obtenção dos índices de vegetação (variáveis explicativas), para cada uma das 54 parcelas amostradas, utilizou-se buffer de $15 \mathrm{~m}$ do centro 
de cada parcela (ArcGis, 10.1). Posteriormente, as variáveis dendrométricas advindas do levantamento de campo (área basal, volume de madeira e biomassa), bem como os índices de vegetação (SR, NDVI, EVI e Savi) registrados para cada parcela amostrada foram correlacionados. Em seguida, os modelos de regressão e de RNAs foram ajustados.

O modelo de regressão adotado foi: $Y=\beta_{0}+\beta_{1} G$ $+\beta_{2} \mathrm{EVI}_{2}+\beta_{3} \mathrm{NDVI}+\beta_{4} \mathrm{Savi}+\beta_{5} \mathrm{SR}$, em que: Y é o volume $\left(\mathrm{m}^{3}\right)$ ou biomassa $(\mathrm{kg})$ por parcela (total e por fuste); $\mathrm{G}$ é a área basal $\left(\mathrm{m}^{2}\right)$ por parcela; SR é o índice de vegetação de razão simples por parcela; NDVI é o índice de vegetação de diferença normalizada por parcela; $\mathrm{EVI}_{2}$ é o índice de vegetação modificado por parcela; Savi é o índice de vegetação ajustado ao solo por parcela; e $\beta_{\mathrm{i}}$ são os estimadores dos parâmetros do modelo. $\mathrm{O}$ ajuste do modelo de regressão foi realizado com o uso do programa Statistica 7.0 (StatSoft Inc., Tulsa, OK, EUA).

Para o ajuste dos modelos de RNAs, tanto as variáveis dendrométricas quanto as obtidas por sensoriamento remoto foram normalizadas linearmente no intervalo de 0 a 1 . As camadas de entrada constituíram-se de 5 neurônios - um para cada variável preditora, em função da variável resposta/saída. Como saída, utilizou-se o volume de madeira e a biomassa (total e do fuste) por parcela.

As redes foram compostas de uma camada oculta, e o número de neurônios nessa camada foi igual a cinco (correspondente ao número de neurônios na camada de entrada). A função sigmoidal foi empregada para ativação das camadas. Como algoritmo de treinamento, utilizou-se o "resilient propagation" (Riedmiller \& Braun,1993), e os parâmetros de treinamento foram: taxa de aprendizagem $(\mu)$ de 0,2 ; e o termo momentum ( $\eta$ ) de 0,9 (Gorgens et al., 2009).

Inicialmente, os pesos de todas as redes foram gerados aleatoriamente (Heaton, 2011). Sequencialmente, o valor individual de atualização evoluiu durante o processo de aprendizado, com base na função do erro. $\mathrm{O}$ treinamento da rede persistiu até que a taxa de erro foi reduzida a uma margem aceitável entre os valores preditos e os reais fornecidos à rede, conhecida como regra delta, ou até atingir o número máximo de épocas ou ciclos (Shiblee et al., 2010).

Para a estimativa de cada variável de interesse, ou seja, volume de madeira total e volume do fuste, biomassa total e biomassa do fuste, foram treinadas 100 redes do tipo perceptrons de múltiplas camadas, comumente conhecidas como MLP ("multilayer perceptron"), no total de 400 redes treinadas. Para o treinamento das redes, adotou-se o método supervisionado, em que as variáveis de entrada e saída são indicadas para a rede. Este método é do tipo "feedforward" e utiliza o algoritmo de fluxo de dados unidirecional, sem ciclos (Haykin, 2001).

Como critério de parada do algoritmo de treinamento, definiu-se o número total de ciclos igual a 3.000 ou erro quadrático médio inferior a $1 \%$, para evitar o número exagerado ou reduzido de ciclos (Chen et al., 2014). Desta forma, o treinamento foi finalizado quando um destes critérios foi atingido, e a melhor rede para estimar cada variável foi selecionada. Para obtenção das redes neurais, utilizou-se o programa NeuroForest, versão 3.0 (NeuroForest, 2014).

Na seleção das RNAs e do modelo de regressão, adotaram-se os seguintes critérios utilizados na verificação da qualidade de ajuste: correlação entre os valores estimados e observados (r); erro-padrão da estimativa (Syx), em percentagem; e análise gráfica dos resíduos. Os critérios utilizados para a validação dos modelos ajustados, bem como para comparar a equação de regressão com a rede neural artificial selecionada, foram: teste do qui-quadrado; erro-padrão da estimativa (Syx), em percentagem; diferença agregada (DA), em percentagem; e erro médio absoluto $\left(\mathrm{E}_{\mathrm{i}}\right)$.

\section{Resultados e Discussão}

As variáveis volume de madeira e biomassa - total e do fuste - apresentaram correlação significativa e positiva com todas as variáveis preditoras envolvidas nos modelos; apenas a variável área basal apresentou alta correlação com as variáveis de interesse $(r>0,9)$. As demais variáveis (SR, NDVI, $\mathrm{EVI}_{2}$ e Savi), todas provenientes de sensoriamento remoto, apresentaram correlações que variaram de fracas a moderadas (Tabela 1).

Bolfe et al. (2012) correlacionaram variáveis espectrais e estoque de carbono da biomassa aérea, em sistemas agroflorestais, e encontraram correlação de 0,78 para o índice SR, tendo concluído que o SR e o NDVI foram os índices mais eficientes na estimativa da biomassa aérea em sistemas agroflorestais jovens.

Segundo Ponzoni (2001), a não ocorrência de altas correlações entre variáveis dendrométricas e variáveis provenientes de sensoriamento remoto 
pode ser explicada pelo aspecto da cobertura vegetal gerada por uma imagem de satélite, que é fruto de um processo complexo que envolve muitos parâmetros e fatores ambientais. Portanto, o que é efetivamente medido por um sensor remotamente situado, oriundo de determinada vegetação, pode não ser explicado somente pelas características intrínsecas da vegetação, pois, o aspecto de uma imagem inclui também a interferência de vários outros parâmetros e fatores, como efeitos da atmosfera, propriedades do dossel (arquitetura complexa) fontes de radiação, solos e diversidade florística.

Apesar da não ocorrência de altas correlações entre cada variável de interesse e os índices de vegetação

Tabela 1. Média, valor máximo e mínimo, desvio-padrão (DP) e coeficiente de variação para os atributos área basal (G), volume de madeira total (Vt) e de fuste (Vf), biomassa total (Bt) e de fuste (Bf), bem como a correlação de Pearson (r) entre as variáveis de interesse e as preditoras.

\begin{tabular}{lccccc}
\hline Estatística & $\begin{array}{c}\mathrm{G} \\
\left(\mathrm{m}^{2}\right)\end{array}$ & $\begin{array}{c}\mathrm{Vt} \\
\left(\mathrm{m}^{3}\right)\end{array}$ & $\begin{array}{c}\mathrm{Vf} \\
\left(\mathrm{m}^{3}\right)\end{array}$ & $\begin{array}{c}\mathrm{Bt} \\
(\mathrm{kg})\end{array}$ & $\begin{array}{c}\mathrm{Bf} \\
(\mathrm{kg})\end{array}$ \\
\hline Média & 0,6849 & 5,0686 & 3,1827 & 2454,22 & 1186,79 \\
Máximo & 1,4001 & 12,3452 & 7,1130 & 6531,07 & 2846,32 \\
Mínimo & 0,3392 & 2,3838 & 1,5743 & 947,73 & 529,31 \\
DP & 0,2208 & 2,3468 & 1,2888 & 1357,79 & 541,81 \\
$\mathrm{CV}(\%)$ & 32,2 & 46,3 & 40,5 & 55,3 & 45,7 \\
\hline \multicolumn{5}{c}{ Correlação entre variáveis de interesse e preditoras } \\
$\mathrm{G}\left(\mathrm{m}^{2}\right)$ & - & $0,96^{*}$ & $0,96^{*}$ & $0,91^{*}$ & $0,91^{*}$ \\
EVI & - & $0,49^{*}$ & $0,47^{*}$ & $0,53^{*}$ & $0,54^{*}$ \\
$\mathrm{NDVI}^{2}$ & - & $0,48^{*}$ & $0,46^{*}$ & $0,53^{*}$ & $0,53^{*}$ \\
Savi & - & $0,48^{*}$ & $0,46^{*}$ & $0,53^{*}$ & $0,53^{*}$ \\
SR & - & $0,51^{*}$ & $0,49^{*}$ & $0,55^{*}$ & $0,55^{*}$ \\
\hline
\end{tabular}

*Significativo a $5 \%$ de probabilidade. $\mathrm{EVI}_{2}$, índice de vegetação modificada; NDVI, índice de vegetação por diferença normalizada; Savi, índice de ajuste ao solo; SR, índice de vegetação de razão simples. (variáveis preditoras), os modelos ajustados (regressão e redes) apresentaram bom desempenho quanto às estimativas de volume de madeira e biomassa (total e do fuste), com baixos valores para erro-padrão da estimativa e altos valores para coeficiente de correlação (Tabela 2).

Embora haja relação direta entre índices de vegetação e produção (Schlerf et al., 2005), os altos valores de $\mathrm{r}$ encontrados nos ajustes dos modelos de regressão foram influenciados pela variável área basal, em função de sua alta correlação com cada variável independente ou resposta $(>0,9)$. No entanto, Lima Júnior et al. (2014), ao utilizar equações alométricas para estimar biomassa lenhosa em caatinga, em função de índices de vegetação, verificaram que a regressão linear entre biomassa e NDVI resultou no coeficiente de correlação de 0,83 e no erro-padrão da estimativa de $31 \%$. Hall et al. (2006) e Watzlawick et al. (2009) também utilizaram dados de sensores multiespectrais, na estimativa do volume de madeira, e encontraram valores de $r$ respectivamente entre 0,58 e 0,83 e 0,75 0,85 .

No presente estudo, as estatísticas obtidas $-\mathrm{r}$ de 0,90 a 0,98 e Syx de 9,72 a $22,76 \%$ - pelos ajustes das equações de regressão são consideradas satisfatórias e superiores às encontradas por Watzlawick et al. (2009), Almeida et al. (2014) e Ferraz et al. (2014). A superioridade destas estatísticas pode estar relacionada tanto à alta intensidade amostral $(18 \%$ da área foi amostrada) quanto às características da resolução espacial e espectral do sensor LISS-III e às características da vegetação estudada. $\mathrm{O}$ efeito das características ambientais e do tipo de sensor, na predição do volume de madeira e da biomassa

Tabela 2. Estimativa dos parâmetros dos modelos de regressão ajustados $\left(\beta_{0}, \beta_{1}, \beta_{2}, \beta_{3}, \beta_{4}\right.$ e $\left.\beta_{5}\right)$, variáveis de entrada $(G$, $\mathrm{EVI}_{2}, \mathrm{NDVI}$, Savi e SR) no procedimento de redes, especificações das redes (número de neurônio e número de camadas) e estatísticas de ajuste e precisão dos modelos.

\begin{tabular}{|c|c|c|c|c|c|c|c|c|c|c|c|c|c|c|}
\hline \multirow[t]{2}{*}{ Variável } & \multicolumn{6}{|c|}{ Modelo de regressão (coeficientes ajustados) } & \multicolumn{2}{|c|}{ Estatísticas } & \multirow[t]{2}{*}{ Rede } & \multicolumn{3}{|c|}{ Neurônios por camada } & \multicolumn{2}{|c|}{ Estatísticas } \\
\hline & $\beta_{0}$ & $\beta_{1}$ & $\beta_{2}$ & $\beta_{3}$ & $\beta_{4}$ & $\beta_{5}$ & $\mathrm{r}$ & Syx $(\%)$ & & Entrada & Oculta & Saída & $\mathrm{r}$ & Syx $(\%)$ \\
\hline Vt de madeira & $-83,16$ & 10,14 & $-449,32$ & $-1418,38$ & 1502,17 & 27,47 & 0,96 & 11,92 & R.vt & 5 & 5 & 1 & 0,99 & 4,93 \\
\hline Volume do fuste & $-12,81$ & 5,61 & $-49,39$ & $-1170,44$ & 855,46 & 1,45 & 0,97 & 9,72 & R.vf & 5 & 5 & 1 & 0,99 & 4,83 \\
\hline Biomassa total & $-39791,07$ & 5559,13 & $-194422,33$ & $-1868219,64$ & 1501945,54 & 10130,89 & 0,91 & 22,76 & R.bt & 5 & 5 & 1 & 0,97 & 8,92 \\
\hline Biomassa do fuste & $-334,22$ & 2248,89 & 14472,86 & $-786663,52$ & 517795,72 & $-2138,53$ & 0,92 & 16,80 & R.bf & 5 & 5 & 1 & 0,98 & 7,96 \\
\hline
\end{tabular}

r, correlação entre os valores estimados e observados; Syx, erro-padrão da estimativa; R.vt, rede ajustada para a estimativa do volume de madeira total; R.vf, rede ajustada para estimativa do volume de fuste; R.bt, rede ajustada para estimativa da biomassa total; R.bf, rede ajustada para estimativa da biomassa de fuste; G, área basal; $\mathrm{EVI}_{2}$, índice de vegetação modificada; NDVI, índice de vegetação por diferença normalizada; Savi, índice de ajuste ao solo; SR, índice de vegetação de razão simples. Vt, volume total. 
florestal, também foi avaliado por Muukkonen \& Heiskanen (2005) e Cutler et al. (2012). Esses autores utilizaram dados de campo e de sensores remotos, em ajustes de modelos de regressão e de redes neurais, e verificaram a necessidade de ajustes diferentes por tipo de vegetação e por características ambientais.

As RNAs também apresentaram alta precisão, com valores de $r \geq 0,98$ e Syx inferiores a 9\%. A eficiência das redes neurais na estimativa da biomassa florestal já foi observada em vários estudos, como os dos seguintes autores: Foody et al. (2001), em florestas tropicais no nordeste de Bornéu, com imagens do sensor TM/ Landsat 5, Schoeninger et al. (2008), em Floresta Ombrófila Densa, no Estado de Santa Catarina; Cutler et al. (2012), em florestas tropicais no Brasil, Malásia e Tailândia, com uso de uma combinação de imagem textural e dados Landsat/TM; e Ferraz et al. (2014), em Floresta Estacional Semidecidual Montana, no Município de Viçosa, MG. Em todos estes trabalhos, foram encontrados valores de $\mathrm{R}$ superiores a $0,85 \mathrm{e}$ Syx inferiores a $19 \%$.

No entanto, mesmo que as estatísticas de qualidade de ajuste apresentadas sejam boas indicadoras para a seleção dos modelos, a análise gráfica de resíduo é quesito fundamental na escolha de um modelo, considerando-se que erros de tendência podem ocorrer em determinada amplitude de classe da variável resposta e não ser detectados pelas demais estatísticas.

A análise gráfica dos resíduos mostra que ambos os modelos ajustados (regressão e redes) conseguiram estimar de forma confiável o volume de madeira e a biomassa (total e do fuste), para cada uma das 40 parcelas utilizadas nos ajustes (Figura 1). Todavia, verifica-se ligeira superioridade das RNAs em estimar os valores de volume de madeira e biomassa. Essa superioridade foi corroborada pela análise gráfica dos resíduos, em que os erros oriundos do procedimento de redes sempre foram inferiores (em geral menores que $\pm 20 \%$ ) e distribuídos de forma mais homogênea. Este comportamento também foi observado para as equações de regressão, porém, a distribuição residual mostrou-se mais dispersa do que para as RNAs.

Ambos os modelos ajustados (regressão e redes) mantiveram os erros de superestimativa e subestimativa em torno de $40 \%$ para volume de madeira e $55 \%$ para a biomassa, embora os vieses decorrentes dos ajustes por regressão tenham sempre apresentado valores mais próximos dos extremos.
Estes resultados foram semelhantes aos encontrados por Muukkonen \& Heiskanen (2005), que estimaram o volume de madeira e a biomassa de florestas boreais na Finlândia, com dados do satélite Aster combinados com dados de inventário florestais.

Segundo Egrioglu et al. (2014), a ligeira superioridade das RNAs é atribuída principalmente à não exigência de alguns pressupostos estatísticos como a normalidade ou linearidade dos dados, além de sua eficácia na generalização de formas e padrões, mesmo quando os dados de treinamento contenham ruídos.

Com base nas estatísticas que indicam a precisão dos modelos (Tabela 2) e na análise gráfica dos resíduos (Figura 1), verifica-se que os índices de vegetação $\left(\mathrm{EVI}_{2}, \mathrm{NDVI}\right.$, Savi e SR) oriundos de imagem do satélite ResourceSat1, correlacionados à área basal, apresentaram eficácia nas estimativas do volume de madeira e biomassa, o que corrobora os resultados de Nichol \& Sarker (2011). Consequentemente, os índices de vegetação e a área basal possibilitam as estimativas das variáveis dendrométricas de interesse em $100 \%$ da floresta (Almeida et al., 2014), seja por regressão ou RNA. Todavia, deve-se mencionar a potencialidade e a ligeira superioridade das RNAs em estimar volume de madeira e biomassa, considerando-se que todas as estatísticas geradas pelas redes foram superiores às da análise de regressão.

A utilização de RNA associada a imagens de satélites vem se tornando ferramenta promissora na estimativa de variáveis dendrométricas de difícil obtenção em florestas (altura, volume, biomassa e carbono), conforme destacado por Schoeninger et al. (2008) e Ferraz et al. (2014).

$\mathrm{O}$ teste de qui-quadrado não detectou diferenças significativas entre os valores estimados pelos modelos ajustados e seus respectivos valores reais $(p>0,05)$, o que indica que ambos os modelos ajustados são válidos e confiáveis para estimativas de volume de madeira e biomassa - total e do fuste, por unidade de área -, no cerradão estudado, tendo-se como variáveis preditoras a área basal e os índices de vegetação (EVI 2, NDVI, Savi e SR) obtidos por sensoriamento remoto (Tabela 2). Estatisticamente, os modelos de regressão e as RNAs não diferiram entre si, resultado este semelhante ao encontrado por Muukkonen \& Heiskanen (2005). 

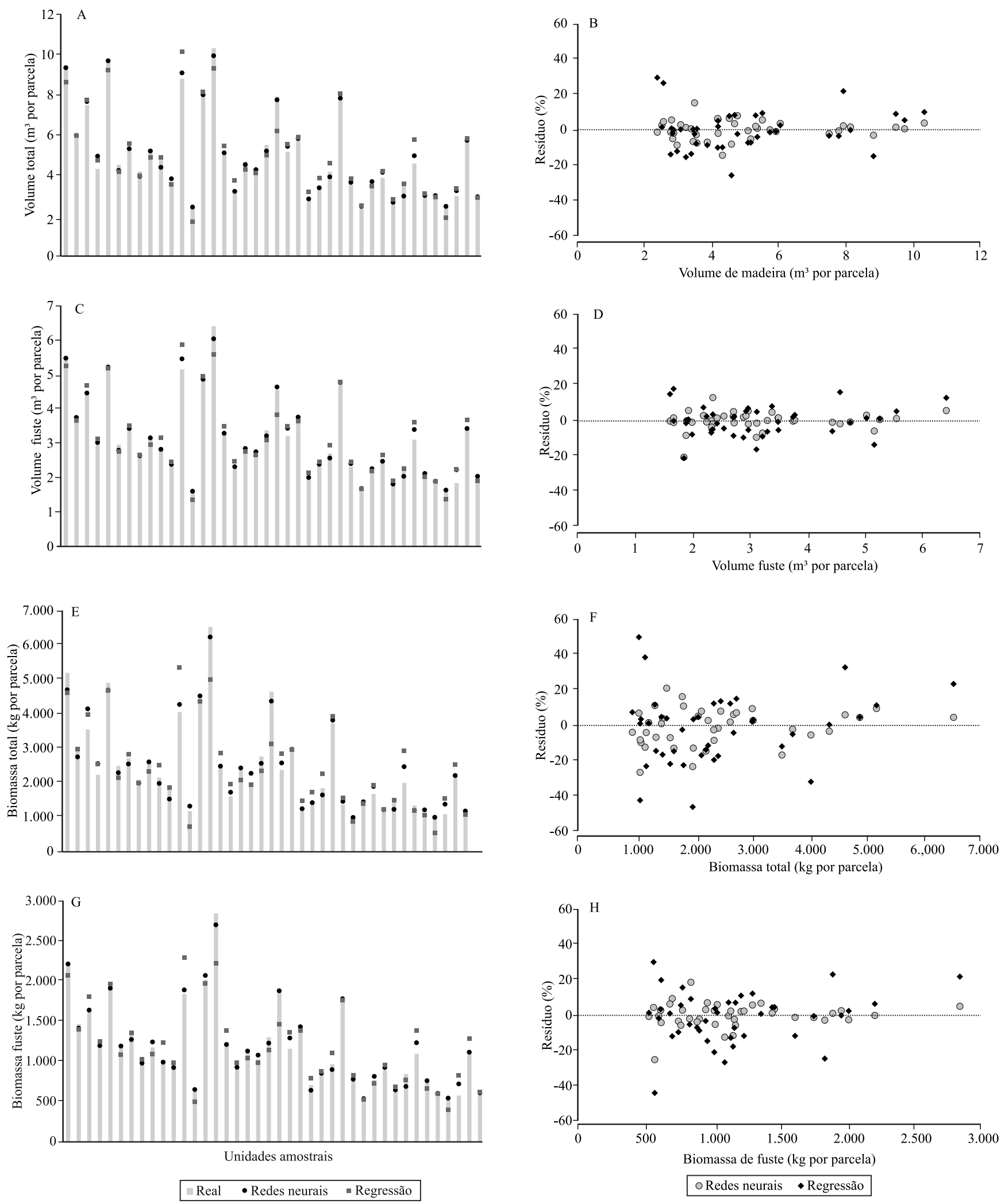

Figura 1. Comportamento dos modelos de regressão e redes na estimativa das variáveis volume de madeira e biomassa (total e do fuste), comparados com os valores reais (A, C, E, G), e os correspondentes gráficos de distribuição residual (B, D, F, H). 
Ao aplicar os modelos ajustados nos dados separados para validação, verificou-se que as equações de regressão apresentaram leve aumento no erro-padrão da estimativa, em relação ao valor gerado pelo ajuste, ou seja: para o volume de madeira total, o erro passou de $11,92 \%$ para $12,34 \%$; para o volume do fuste, o erro passou de $9,72 \%$ para $11,56 \%$; e para a biomassa total e a biomassa do fuste, o erro aumentou de $22,76 \%$ para $23,82 \%$ e de $16,80 \%$ para $18,01 \%$, respectivamente; na aplicação das RNAs, os aumentos foram respectivamente de, $4,93 \%$ para $6,01 \%, 4,83 \%$ para $5,88 \%, 8,92 \%$ para $13,35 \%$ e de $7,96 \%$ para 10,35\% (Tabela 3). Estes aumentos no erro-padrão da estimativa são perfeitamente aceitáveis, já que o número de parcelas amostradas reduziu-se em $75 \%$ (de 40 para 14 parcelas).

A diferença agregada, que corresponde à diferença entre o somatório dos valores observados com os estimados, apresentou valores negativos tanto para volume de madeira total $(-12,72 \%)$ quanto para volume do fuste $(-15,29 \%)$. O mesmo fato foi observado para biomassa total $(-18,45 \%)$ e do fuste $(-17,92 \%)$. Tais valores evidenciam a tendência de a equação de regressão superestimar os valores destas variáveis. As RNAs geraram comportamento inverso, com valores positivos da diferença agregada para o volume de madeira total e fuste $(3,41 \%$ e $8,58 \%$, respectivamente) e para biomassa total e do fuste $(8,29 \%$ e $8,05 \%$ respectivamente), o que mostra a tendência de subestimar estas variáveis, porém com valores mais próximos aos reais.

Os valores médios do resíduo, gerados a partir dos modelos de regressão ajustados, foram de $-0,048 \mathrm{~m}^{3} \mathrm{e}$ $-0,051 \mathrm{~m}^{3}$ para volume de madeira total e volume do fuste respectivamente. Valores de $\mathrm{E}_{\mathrm{i}}$ próximos de zero são desejáveis, pois mostram a capacidade dos modelos de estimar as variáveis de interesse com acurácia. Para a biomassa total e do fuste, estes valores foram iguais a $-70,36 \mathrm{~kg}$ e $-46,35 \mathrm{~kg}$, respectivamente. Quando se aplicaram as RNAs, os valores médios de $\mathrm{E}_{\mathrm{i}}$ foram de: $0,013 \mathrm{~m}^{3}$, para volume de madeira total, e $0,020 \mathrm{~m}^{3}$ para volume do fuste; e 15,22 kg para biomassa total, e 7,31 kg, para fuste.

Observa-se que ambos os modelos ajustados (redes e regressão) tiveram seus resíduos distribuídos de forma homogênea e sem qualquer tendência (Figura 2). Levando-se em conta a grande heterogeneidade das florestas nativas, condicionada por variações de sítio, idade, forma, densidade e riqueza florística, podemse considerar satisfatórias, precisas e válidas as estimativas geradas pelas duas categorias de ajuste. Contudo, vale ressaltar que, para todas as predições,

Tabela 3. Atributos médios, mínimos e máximos, valores reais e valores estimados por equação de regressão e por redes neurais, para as variáveis volume de madeira e biomassa por parcela, e estatísticas para a validação.

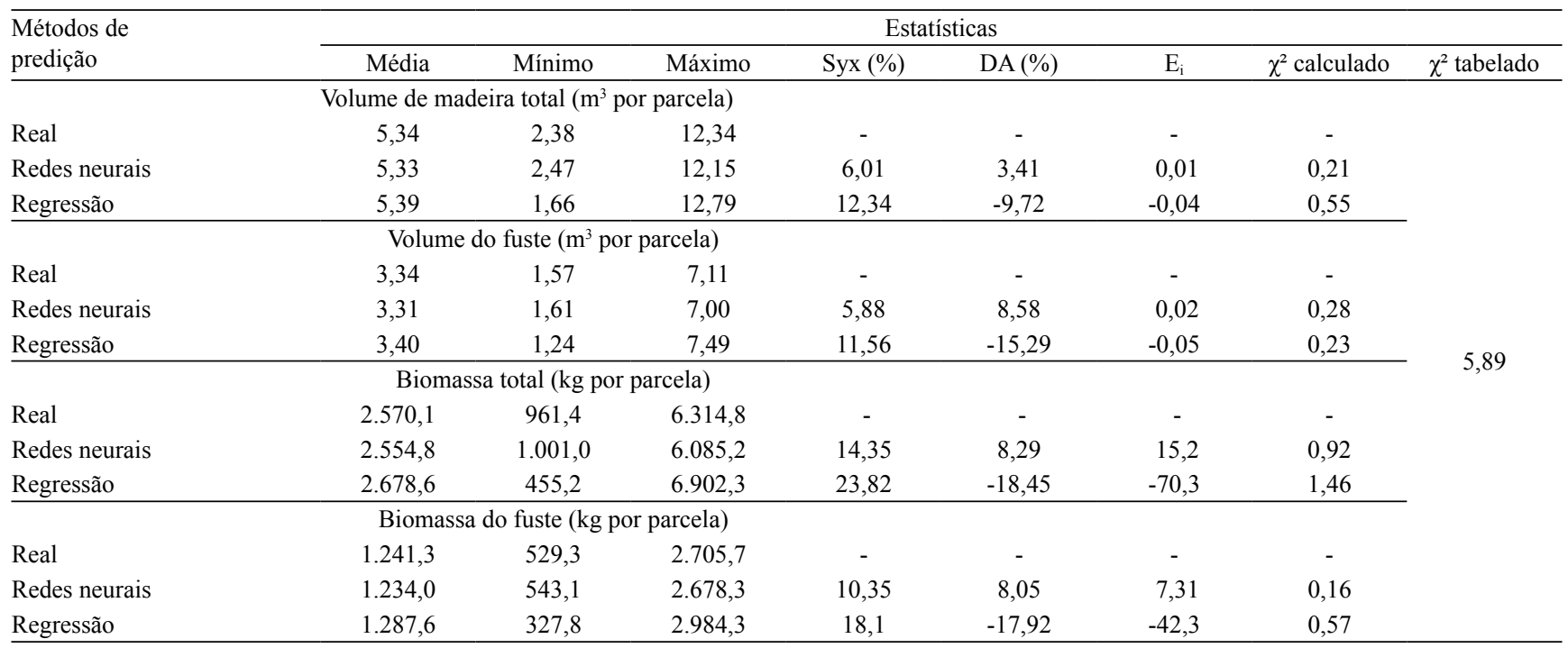

Syx, erro-padrão da estimativa; DA, diferença agregada; $\mathrm{E}_{\mathrm{i}}(\mathrm{Abs})$, erro médio absoluto; $\chi^{2}$ (teste qui-quadrado) tabelado, 13 graus de liberdade da amostra $\mathrm{e}$ $95 \%$ de probabilidade. 
as RNAs foram melhores, conforme mostrado pelos critérios de ajuste, o que corrobora os resultados encontrados por Schoeninger et al. (2008) e Ferraz et al. (2014).

Os totais estimados para produção em volume de madeira e biomassa, para o fragmento de cerradão no Parque Estadual do Lajeado, em Palmas, TO (Tabela 4), são compatíveis com os obtidos em um estudo realizado em áreas de cerradão no Estado de Minas Gerais, onde se estimaram, em média, $117 \mathrm{~m}^{3} \mathrm{ha}^{-1}$ para volume de madeira total e $57 \mathrm{Mg} \mathrm{ha}^{-1}$ para biomassa total (Morais et al., 2013). Isso indica que ambos os modelos ajustados (regressão e de redes), em função da área basal e dos índices de vegetação obtidos a partir das imagens do satélite ResourceSat1 (IRS-P6), mostraram-se eficazes em estimar as variáveis volume de madeira e biomassa lenhosa. Este resultado impacta de forma positiva na redução do tempo e custo dos inventários florestais, o que possibilita estimativas indiretas precisas a partir de dados derivados de imagens de satélite.

Porém, ressalta-se que os resultados obtidos são específicos para a fitofisionomia estudada, para o local e para a estrutura e composição florística registradas. A inclusão da variável área basal no modelo é desejável, pois é um atributo de fácil obtenção quanto à vegetação e altamente correlacionado às produções em volume, biomassa e carbono.

Todavia, novos trabalhos devem ser realizados com outras variáveis preditoras. Outros índices de vegetação devem ser avaliados, bem como novos sensores orbitais, com melhor resolução espacial e temporal. Sugere-se ainda testar distintas configurações de redes neurais, com o objetivo de se obter maior correlação entre os dados dendrométricos e dados digitais e, consequentemente, maior acurácia nas estimativas das variáveis de interesse da floresta.
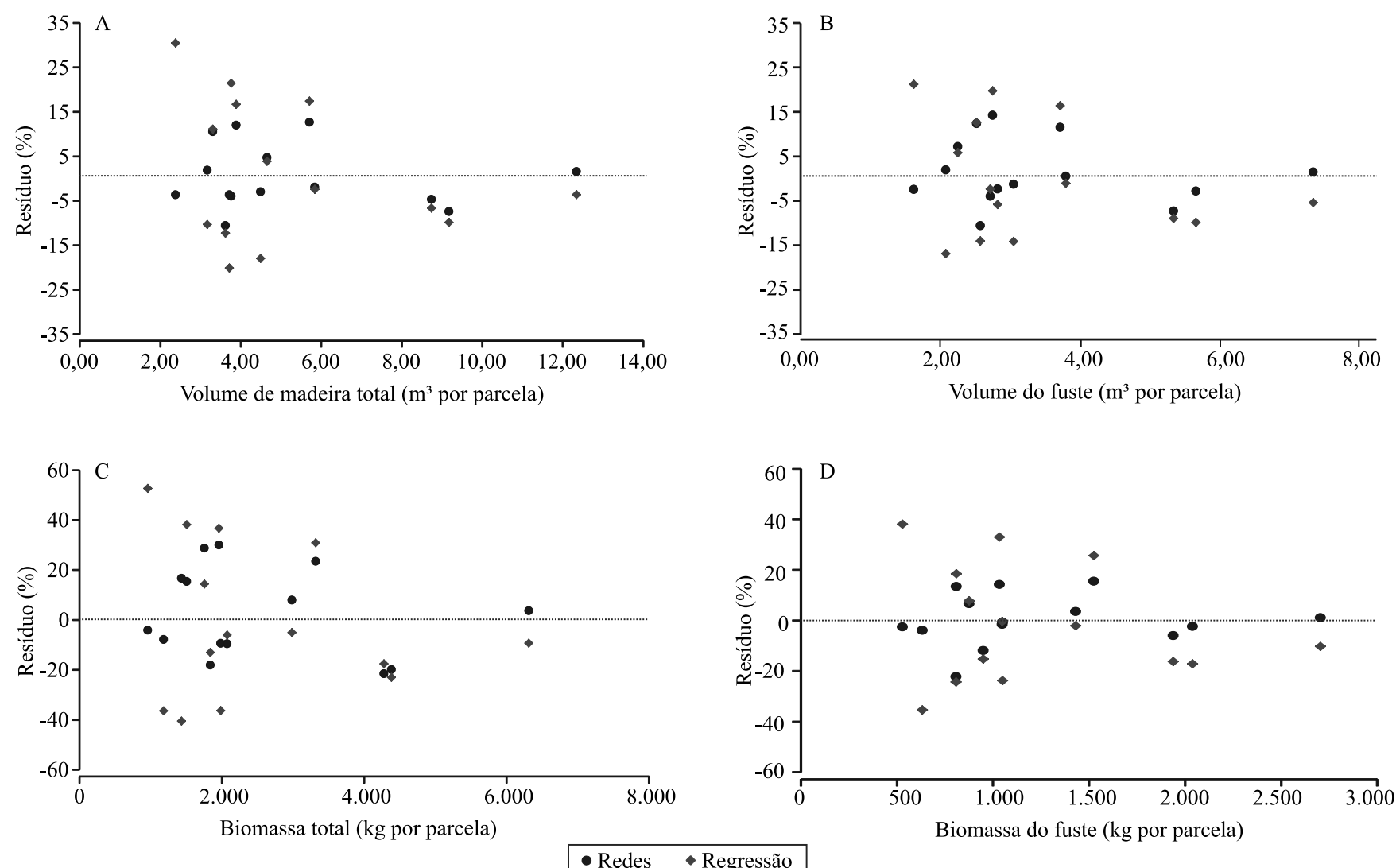

Figura 2. Gráficos de resíduos para volume de madeira total (A) e do fuste (B) e para biomassa total (C) e do fuste (D), obtidos a partir dos modelos ajustados e validados de regressão e de redes. 
Tabela 4. Atributos médios, mínimos e máximos, reais e estimados pelas duas categorias de ajuste, para as variáveis volume de madeira e biomassa total e por compartimento.

\begin{tabular}{lccc}
\hline Atributos & \multicolumn{3}{c}{ Métodos de predição } \\
\cline { 2 - 4 } & Regressão & Redes & Mensurado \\
\hline Volume de madeira total $\left(\mathrm{m}^{3} \mathrm{ha}^{-1}\right)$ & 127,48 & 126,03 & 126,34 \\
Volume de fuste $\left(\mathrm{m}^{3} \mathrm{ha}^{-1}\right)$ & 80,39 & 78,28 & 78,98 \\
Volume de copa $\left(\mathrm{m}^{3} \mathrm{ha}^{-1}\right)$ & 47,09 & 47,74 & 47,35 \\
\hline Biomassa total $\left(\mathrm{Mg} \mathrm{ha}^{-1}\right)$ & 63,80 & 60,85 & 61,21 \\
Biomassa de fuste $\left(\mathrm{Mg} \mathrm{ha}^{-1}\right)$ & 30,67 & 29,39 & 29,56 \\
Biomassa de copa $\left(\mathrm{Mg} \mathrm{ha}^{-1}\right)$ & 33,13 & 31,46 & 31,65 \\
\hline
\end{tabular}

\section{Conclusões}

1. Independentemente de diversidade florística, heterogeneidade estrutural e complexidade do dossel, a área basal e os índices de vegetação derivados de imagens obtidas pelo sensor LISS-III, a bordo do satélite ResourceSat1, são eficazes nas estimativas do volume de madeira e biomassa em áreas de cerradão.

2. Estimativas precisas de volume de madeira e biomassa para a vegetação lenhosa, em área de cerradão, são obtidas a partir de modelos de regressão e de redes neurais artificiais (RNA), ajustados em função da área basal e de índices de vegetação gerados por sensoriamento remoto, contudo, as RNAs são mais acuradas.

\section{Agradecimentos}

Ao Conselho Nacional de Desenvolvimento Científico e Tecnológico (CNPq) e à Universidade de Brasília, pelo apoio financeiro; ao Instituto Natureza do Tocantins (Naturatins), pela permissão para a realização da pesquisa e pelo apoio logístico.

\section{Referências}

ALMEIDA, A.Q. de; MELlO, A.A. de; DÓRIA NETO, A.L.; FERRAZ, R.C. Relações empíricas entre características dendrométricas da Caatinga brasileira e dados TM Landsat 5. Pesquisa Agropecuária Brasileira, v.49, p.306-315, 2014. DOI: 10.1590/S0100-204X2014000400009.

BACCINI, A.; FRIEDL, M.A.; WOODCOCK, C.E.; ZHU, Z. Scaling field data to calibrate and validate moderate spatial resolution remote sensing models. Photogrammetric Engineering and Remote Sensing, v.73, p.945-954, 2007. DOI: 10.14358/ PERS.73.8.945.
BOLFE, E.L.; BATISTELLA, M.; FERREIRA, M.C. Correlação de variáveis espectrais e estoque de carbono da biomassa aérea de sistemas agroflorestais. Pesquisa Agropecuária Brasileira, v.47, p.1261-1269, 2012. DOI: 10.1590/S0100-204X2012000900011.

CHEN, W.-C.; TSENG, L.-Y.; WU, C.-S. A unified evolutionary training scheme for single and ensemble of feedforward neural network. Neurocomputing, v.143, p.347-361, 2014. DOI: 10.1016/j. neucom.2014.05.057.

CUTLER, M.E.J.; BOYD, D.S.; FOODY, G.M.; VETRIVEL, A. Estimating tropical forest biomass with a combination of SAR image texture and Landsat TM data: an assessment of predictions between regions. ISPRS Journal of Photogrammetry and Remote Sensing, v.70, p.66-77, 2012. DOI: 10.1016/j.isprsjprs.2012.03.011.

DJOMO, A.N.; KNOHL, A.; GRAVENHORST, G. Estimations of total ecosystems carbon pools distribution and carbon biomass current annual increment of a moist tropical forest. Forest Ecology and Management, v.261, p.1448-1459, 2011. DOI: 10.1016/j. foreco.2011.01.031.

EGRIOGLU, E.; YOLCU, U.; ALADAG, C.H.; BAS, E. Recurrent multiplicative neuron model artificial neural network for non-linear time series forecasting. Procedia - Social and Behavioral Sciences, v.109, p.1094-1100, 2014. DOI: 10.1016/j.sbspro.2013.12.593.

FERRAZ, A.S.; SOARES, V.P.; SOARES, C.P.B.; RIBEIRO, C.A.A.S.; BINOTI, D.H.B.; LEITE, H.G. Estimativa do estoque de biomassa em um fragmento florestal usando imagens orbitais. Floresta e Ambiente, v.21, p.286-296, 2014. DOI: 10.1590/2179-8087.052213.

FOODY, G.M.; CUTLER, M.E.; MCMORROW, J.; PELZ, D.; TANGKI, H.; BOYD, D.S.; DOUGLAS, I. Mapping the biomass of Bornean tropical rain forest from remotely sensed data. Global Ecology and Biogeography, v.10, p.379-387, 2001. DOI: 10.1046/j. 1466-822X.2001.00248.x

GORGENS, E.B.; LEITE, H.G.; SANTOS, H. do N.; GLERIANI, J.M. Estimação do volume de árvores utilizando redes neurais artificiais. Revista Árvore, v.33, p.1141-1147, 2009. DOI: 10.1590/ S0100-67622009000600016.

GUILHERME, F.A.G.; NAKAJIMA, J.N. Estrutura da vegetação arbórea de um remanescente ecotonal urbano floresta-savana no Parque do Sabiá, em Uberlândia, MG. Revista Árvore, v.31, p.329-338, 2007. DOI: 10.1590/S0100-67622007000200016.

HALL, R.J.; SKAKUN, R.S.; ARSENAULT, E.J.; CASE, B.S. Modeling forest stand structure attributes using Landsat ETM+ data: application to mapping of aboveground biomass and stand volume. Forest Ecology and Management, v.225, p.378-390, 2006. DOI: 10.1016/j.foreco.2006.01.014.

HAYKIN, S. Redes neurais: princípios e prática. 2.ed. Porto Alegre: Bookman, 2001. 898p.

HEATON, J. Programming neural networks with Encog3 in Java. 2.ed. Chesterfield: Heaton Research, 2011. 240p.

HUETE, A.R. A soil-adjust vegetation index (Savi). Remote Sensing of Environment, v.25, p.295-309, 1988. DOI: 10.1016/0034-4257(88)90106-X.

HUSCH, B.; MILLER, C.L.; BEERS, T.W. Forest mensuration. $3^{\text {rd }}$ ed. New York: J. Willey, 1982. 402p. 
JIANG, Z.; HUETE, A.R.; DIDAN, K.; MIURA, T. Development of a two-band enhanced vegetation index without a blue band. Remote Sensing of Environment, v.112, p.3833-3845, 2008. DOI: 10.1016/j.rse.2008.06.006.

JORDAN, C.F. Derivation of leaf-area index from quality of light on the forest floor. Ecology, v.50, p.663-666, 1969. DOI: $10.2307 / 1936256$.

LIMA JÚNIOR, C. de; ACCIOLY, L.J. de O.; GIONGO, V.; LIMA, R.L.F de A.; SAMPAIO, E.V. de S.B.; MENEZES, R.S.C. Estimativa de biomassa lenhosa da caatinga com uso de equações alométricas e índice de vegetação. Scientia Forestalis, v.42, p.289-298, 2014.

MENDONÇA, R.C. de; FELFILI, J.M.; WALTER, B.M.T.; SILVA JÚNIOR, M.C. da; REZENDE, A.V.; FILGUEIRAS, T. de S.; NOGUEIRA, P.E.; FAGG, C.W. Flora vascular do bioma Cerrado: checklist com 12.356 espécies. In: SANO, S.M.; ALMEIDA, S.P. de; RIBEIRO, J.F. (Ed.). Cerrado: ecologia e flora. Brasília: Embrapa Informação Tecnológica; Planaltina: Embrapa Cerrados, 2008. v.2, p.421-442.

MIGUEL, E.P. Caracterização da flora e da produção em volume, biomassa e carbono da vegetação arbórea em área de cerradão no Estado do Tocantins. 2014. 81p. Tese (Doutorado) - Departamento de Engenharia Florestal, Universidade de Brasília, Brasília.

MORAIS, V.A.; SCOLFORO, J.R.S.; SILVA, C.A.; MELLO, J.M. de; GOMIDE, L.R.; OLIVEIRA, A.D. de. Carbon and biomass stocks in a fragment of cerradão in Minas Gerais state, Brazil. Cerne, v.19, p.237-245, 2013. DOI: 10.1590/S0104-77602013000200007.

MUUKKONEN, P.; HEISKANEN, J. Estimating biomass for boreal forests using ASTER satellite data combined with standwise forest inventory data. Remote Sensing of Environment, v.99, p.434-447, 2005. DOI: 10.1016/j.rse.2005.09.011.

NEUROFOREST. Disponível em: <http://neuroforest.ucoz.com/>. Acesso em: 10 out. 2014.

NICHOL, J.E.; SARKER, M.L.R. Improved biomass estimation using the texture parameters of two high-resolution optical sensors. IEEE Transactions on Geoscience and Remote Sensing, v.49, p.930-948, 2011. DOI: 10.1109/TGRS.2010.2068574.

PÉLLICO NETTO, S.; BRENA, D.A. Inventário florestal. Curitiba, 1997. 316p.

PONZONI, F.J. Comportamento espectral da vegetação. In: MENESES, P.R.; MADEIRA NETTO, J. da S. (Ed.). Sensoriamento remoto: reflectância dos alvos naturais. Brasília: Ed. da UnB; Planaltina: Embrapa Cerrados, 2001. p.157-199.

RASCHE, L.; FAHSE, L.; BUGMANN, H. Key factors affecting the future provision of tree-based forest ecosystem goods and services. Climatic Change, v.118, p.579-593, 2013. DOI: 10.1007/ s10584-012-0664-5.

REZENDE, A.V.; VALE, A.T. do; SANQUETTA, C.R.; FIGUEIREDO FILHO, A.; FELFILI, J.M. Comparação de modelos matemáticos para estimativa do volume, biomassa e estoque de carbono da vegetação lenhosa de um cerrado sensu stricto em Brasília, DF. Scientia Forestalis, n.71, p.65-76, 2006.

RIBEIRO, J.F.; WALTER, B.M.T. As principais fitofisionomias do bioma Cerrado. In: SANO, S.M.; ALMEIDA, S.P. de; RIBEIRO, J.F. (Ed.). Cerrado: ecologia e flora. Brasília: Embrapa Informação Tecnológica; Planaltina: Embrapa Cerrados, 2008. cap.6, p.151-212.

RIEDMILLER, M.; BRAUN, H. A direct adaptive method for faster backpropagation learning: the RPORP algorithm. In: IEEE INTERNATIONAL CONFERENCE ON NEURAL NETWORKS, 1993, San Francisco. Proceedings. New York: IEEE, 1993. p.586-591. DOI: 10.1109/ICNN.1993.298623.

ROUSE, J.W.; HAAS, R.H.; SCHELL, J.A.; DEERING, D.W. Monitoring vegetation systems in the great plains with ERTS. In: EARTH RESOURCES TECHNOLOGY SATELLITE-1 SYMPOSIUM, 3., 1973, Washington. Proceedings. Washington: NASA, 1974. v.1, p.309-317.

SANTOS, H.G. dos; JACOMINE, P.K.T.; ANJOS, L.H.C. dos; OLIVEIRA, V.A. de; LUMBRERAS, J.F.; COELHO, M.R.; ALMEIDA, J.A. de; CUNHA, T.J.F.; OLIVEIRA, J.B. de (Ed.). Sistema brasileiro de classificação de solos. 3.ed. Brasília: Embrapa, 2013. 353p.

SCHLERF, M.; ATZBERGER, C.; HILL, J. Remote sensing of forest biophysical variables using HyMap imaging spectrometer data. Remote Sensing of Environment, v.95, p.177-194, 2005. DOI: $10.1016 /$ j.rse.2004.12.016.

SCHOENINGER, E.R.; KOEHLER, H.S.; BOTELHO, M.F.; WATZLAWICK, L.F.; OLIVEIRA, P.C. de. Uso de redes neurais artificiais para mapeamento de biomassa e carbono orgânico no componente arbóreo de uma Floresta Ombrófila Densa. Ambiência, v.4, p.179-195, 2008.

SHIBLEE, M.D.; CHANDRA, B.; KALRA, P.K. Learning of geometric mean neuron model using resilient propagation algorithm. Expert Systems with Applications, v.37, p.7449-7455, 2010. DOI: 10.1016/j.eswa.2010.04.018.

SOLORZANO, A.; PINTO, J.R.R.; FELFILI, J.M.; HAY, J.D.V. Perfil florístico e estrutural do componente lenhoso em seis áreas de cerradão ao longo do bioma Cerrado. Acta Botanica Brasilica, v.26, p.328-341, 2012. DOI: 10.1590/S0102-33062012000200009.

VIVALDI, D.D.; BAPTISTA, G.M. de M.; MENESES, P.R. Avaliação dos processamentos de crosstalk e de correção atmosférica em dados ASTER para identificação da relação mineralógica caulinita/(caulinita + gibbsita) em solos no Município de São João d'Aliança (GO). Brazilian Journal of Geology, v.43, p.571-582, 2013. DOI: 10.5327/Z2317-48892013000300011.

WATZLAWICK, L.F.; KIRCHNER, F.F.; SANQUETTA, C.R. Estimativa de biomassa e carbono em floresta com araucária utilizando imagens do satélite Ikonos II. Ciência Florestal, v.19, p.169-181, 2009.

$\overline{\text { Recebido em } 2 \text { de dezembro de } 2014 \text { e aprovado em } 13 \text { de julho de } 2015}$ 